\title{
Optimization of Medium and Incubation Time in the Production of Antibacterial Compounds by Streptomyces sp. SA404
}

\author{
Larasati $\mathrm{A}^{1}$, Ryandini $\mathrm{D}^{1^{*}}$, Oedjijono $\mathrm{O}^{1}$, and Kusharyati $\mathrm{D} \mathrm{F}^{1}$ \\ ${ }^{I}$ Faculty of Biology, Unsoed, Purwokerto, Indonesia \\ "corresponding author: dini_ryandini@yahoo.com
}

\begin{abstract}
Streptomyces sp. SA404 was isolated from the mangrove rhizosphere in Segara Anakan Cilacap known for its production of antibacterial compounds. The production of antibacterial compounds might be influenced by nutrients ( $\mathrm{C}$ and $\mathrm{N}$ sources) and incubation time. The aims of this study were to know the medium compositions (A: glucose $0.5 \%$, starch $1 \%$, yeast extract $0.2 \%$; B: glucose $0.5 \%$, starch $1 \%$, sodium nitrate $0.2 \%$; C: oatmeal $1 \%$, yeast extract $0.2 \%$; and D: oatmeal $1 \%$, sodium nitrate $0.2 \%$ ), with incubation times of $(7,14$, and 21 days) and their interactions in producing the crude extract of antibacterial compounds. The main parameter was the crude extract weight, with the supporting parameters of glucose concentration, biomass dry weight, filtrate $\mathrm{pH}$, filtrate inhibitory zone diameter, and extract inhibitory zone diameter. The result showed that the medium compositions and incubation times affected the produced crude extract and other supporting parameters. The highest crude extract weight productions were respectively shown by medium A $(0.802 \mathrm{mg})$ with 21 days incubation time $(0.640 \mathrm{mg})$, yet no interaction between them. Antibacterial compounds synthesis with 21 days incubation time and the use of inorganic nitrogen further supports the formation of antibacterial compounds.
\end{abstract}

Keywords: Incubation Time, Antibacterial, Streptomyces sp. SA404.

\section{INTRODUCTION}

Mangrove environment is rich with organic substances functioning as the antibacterial sources producing Streptomyces [1]. Streptomyces sp. SA404 isolated from the mangrove rhizosphere of Segara Anakan Cilacap, was known producing antibacterial compounds. This isolate had the capability of inhibiting the growth of Escherichia coli and Staphylococcus aureus [2]. The secondary metabolites of Streptomyces sp. SA404 were likely synthesized in response to the physiological conditions due to the nutritional factors [3].
The secondary metabolites were synthesized when the nutrients were limited. These conditions served as biochemical signals triggering the antibiotic production. Various microorganisms were known to grow in different environments and had particular growth conditions, like incubation times and nutritional requirement, especially carbon and nitrogen [4]. The antibacterial compounds produced by Streptomyces were affected by $\mathrm{pH}$, nutrients, and incubation time [5].

Carbon and nitrogen were important components for the growth of Streptomyces to produce the antibacterial compounds. The bacterial growth was mostly influenced by the nutritional compositions, especially carbon and nitrogen [4]. The mixture of glucose and starch 
was the best carbon source for the production of antimicrobial compounds [1]. The other carbon source commonly used in the production of antibacterial compounds by Streptomyces was oatmeal [6]. Several different combinations were suggested to culture actinomycetes. Oatmeal was found as a good medium to develop Streptomyces [7].[8], recommended four actinomycetes culture media: oatmeal medium, nitrate medium, starch casein nitrate medium, and potato dextrose medium. Oatmeal was considered as the best medium for Streptomyces growth.

Nitrogen was the other essential nutrient for the growth and synthesis of protein, amino acid, DNA, and RNA. Organic and inorganic nitrogen sources needed for the synthesis of antibacterial compounds were yeast extract and sodium nitrate [9]. Organic and inorganic nitrogen sources played an important role in the synthesis of antibacterial compounds which mostly used yeast extract and sodium nitrate [10].

Antibacterial compounds as the secondary metabolites were synthesized at the stationary phase. The optimization of incubation time might determine the right time to produce the secondary metabolites. The optimization of incubation time was required to produce the antibacterial compounds [11].

The previous research, the optimization of medium and incubation time for Streptomyces sp. SA404 to produce the antibacterial compounds of crude extract was conducted by using medium containing starch $0.5 \%$ or oatmeal $1 \%$ as carbon sources and yeast extract $0.2 \%$ or sodium nitrate $0.2 \%$ as nitrogen sources with the incubation times of 7,14 and 21 days. The highest crude extract $(11.42 \mathrm{~g})$ was obtained from medium containing oatmeal and sodium nitrate incubated during 14 days. In this study, similar series of treatments enriched with glucose $0.5 \%$ were observed, aiming to determine the optimal compositions of medium, incubation time, and their interactions in producing the antibacterial compounds of crude extract by Streptomyces sp. SA404.

\section{MATERIALS AND METHODS}

\subsection{Materials}

The materials used were the isolates of Streptomyces sp. SA404, Escherichia coli, Staphylococcus aureus, media of Starch Casein Nitrate Agar (SCNA), Nutrient Agar (NA), Nutrient Broth (NB), media treatment series (medium A: basal medium, glucose $0.5 \%$, starch $1 \%$, yeast extract $0.2 \%$; medium B: basal medium, glucose $0.5 \%$, starch $1 \%$, sodium nitrate $0.2 \%$; medium $\mathrm{C}$ : basal medium, oatmeal $1 \%$, yeast extract $0.2 \%$; and medium $\mathrm{D}$ : basal medium, oatmeal $1 \%$, sodium nitrate $0.2 \%$ ), NelsonSomogyi reagent, arsenomolybdate reagent, glucose anhydrous, ethyl acetate, ethanol, and alcohol $70 \%$.

The tools used were microbiological glass wares, $6 \mathrm{~mm}$ paper disc, 10-20 $\mu 1$ micropipettes and tips, 10-1000 $\mu 1$ micropipettes and tips, incubator shaker (Jelo Tech IB-5600M), oven (Memmert UN 55), spectrophotometer (Halo Vis-10), centrifuge machine $5415 \mathrm{D}$, analytical balance (Ohaus), hot plate magnetic stirrer (IKA C-Mag HS 10), separated funnel, laminar air flow (Labconco), refrigerator, autoclave (Hirayama HL36AE), milipore syringe, oven, Whatman filter paper no. 1, electrical binocular microscope (Olympus), and corks borer.

The study was conducted in the Microbiology Laboratory, Biology Faculty, Unsoed.

\subsection{Methods}

The research was experimentally conducted using a completely randomized design (CRD) with factorial patterns. Media as the first factor consisted of four types, while the second factor consisted of three incubation times. The treatments were each replicated three times. The main parameter measured was crude extract mass (CEM), supported by the additional parameters: sugar reduction concentration (SRC), mycelium dry weight $(\mathrm{MDW}), \mathrm{pH}$ filtrate $(\mathrm{pH})$, filtrate inhibitory zone (FIZ) diameter, and extract inhibitory zone (EIZ) diameter. The main data was analyzed using ANOVA (Analysis of Variance) and then continued with the post hoc test using Tukey's HSD.

\subsection{Subculture and inoculum preparation [12]}

The isolates of Streptomyces sp. SA404 were sub cultured in SCNA medium, incubated in the room temperature for 7 days. Meanwhile, the isolates of $E$. coli and $S$. aureus were sub cultured in NA medium.

The inoculum of Streptomyces sp. SA404 was prepared by spreading the isolates in SCNA plate medium, were then incubated at the temperature of $30^{\circ} \mathrm{C}$ for 7 days, and formed into plugs using corks borer.

\subsection{Production of antibacterial compounds [13]}

The Streptomyces sp. SA404 plugs were cultivated in $250 \mathrm{~mL}$ of medium A, B, C, D and incubated at $30^{\circ} \mathrm{C}$ respectively for 7,14 , and 21 days. At every end of incubation time, the liquid cultures were filtered to get the mycelium biomass. The filtrate 
was measured for its $\mathrm{pH}$ and the resulted $1.5 \mathrm{~mL}$ was then centrifugated (3000 rpm) for 5 minutes. The supernatan was subject to the inhibitory assay of Escherichia coli and Staphylococcus aureus using the paper disc diffusion method.

\subsection{Mycelium dry weight measurement [13]}

Whatman paper $\left(\mathrm{X}_{1}\right)$ was used to separate the mycelium biomass and filtrate. The mycelium biomass was heated in the oven at the temperature of $70^{\circ} \mathrm{C}$ for 2 hours to get the dry mycelium biomass. The dry biomass was measured as gross mass $\left(\mathrm{X}_{2}\right)$. The mycelium biomass dry weight (MDW) was $\mathrm{X}_{2}-\mathrm{X}_{1}$.

\subsection{Sugar reduction concentration (SRC)} measurement using Nelson-Somogyi Method [14]

Filtrate $1 \mathrm{~mL}$ was prepared in a test tube, added with Nelson-Somogyi reagent $1 \mathrm{~mL}$, heated in the boiling water bath for 20 minutes, immediately cooled to the temperature of $25^{\circ} \mathrm{C}$, added with arsenomolybdate reagent $1 \mathrm{~mL}$, shaken until all $\mathrm{Cu}_{2} \mathrm{O}$ sediments were dissolved, added with distilled water $7 \mathrm{~mL}$, and then shaken until homogeneous. The optical density (OD) of each solution was measured and analyzed using spectrophotometer at the wavelength of $540 \mathrm{~nm}$. The sugar reduction concentration (SRC) culture was determined according to the standard equation.

\subsection{Filtrate inhibition assay [6]}

$E$. coli and $S$. aureus cultures were spread on NA medium. Furthermore, supernatant $1.5 \mathrm{~mL}$ was filtered using millipore syringe. Paper disc was placed on NA surface, dropped with filtrate $20 \mu 1$ and then incubated in the temperature of $37^{\circ} \mathrm{C}$ for 24 hours. The formed inhibition zone (FIZ) was observed since the 8 hours incubation, measured as the average of vertical and horizontal clear zone diameters.

\subsection{Antibacterial compounds extraction and measurement [12]}

Filtrate was extracted twice with ethyl acetate solvent $(1: 1 \mathrm{v} / \mathrm{v})$ in separated funnel for 10 minutes. Furthermore, the extract was evaporated until the crude extract was obtained and kept in a vial bottle which weight was previously measured $\left(X_{\mathrm{v} 1}\right)$. The crude extract obtained was measured as gross mass $\left(\mathrm{X}_{\mathrm{v} 2}\right)$. Meanwhile, the crude extract mass (CEM) was $\mathrm{X}_{\mathrm{v} 2}-\mathrm{X}_{\mathrm{v} 1}$.

\subsection{Extract inhibition assay [12]}

The E. coli $(10 \mathrm{hrs})$ and $S$. aureus $(8 \mathrm{hrs})$ liquid cultures were spread on NA medium. Paper disc was placed on the medium surface and dropped with crude extract $20 \mu \mathrm{l}$, then incubated at the temperature of $37^{\circ} \mathrm{C}$ for 24 hours. The extract inhibition zone (EIZ) diameter was measured since 8 hours incubation and measured as the average of vertical and horizontal clear zone diameter.

\section{RESULT AND DISCUSSION}

The result showed that the production of secondary metabolites of Streptomyces sp. SA404 was affected by the compositions of medium and incubation time. The highest production of CEM was shown by medium $\mathrm{A}(0.802 \mathrm{mg})$ with 21 days incubation $(0.640 \mathrm{mg})(\mathrm{p}<0.05)$. There was no interaction between medium type and incubation time of Streptomyces sp. SA404 in producing the antibacterial compounds of crude extract $(p>0.05)$ (Figure 1).
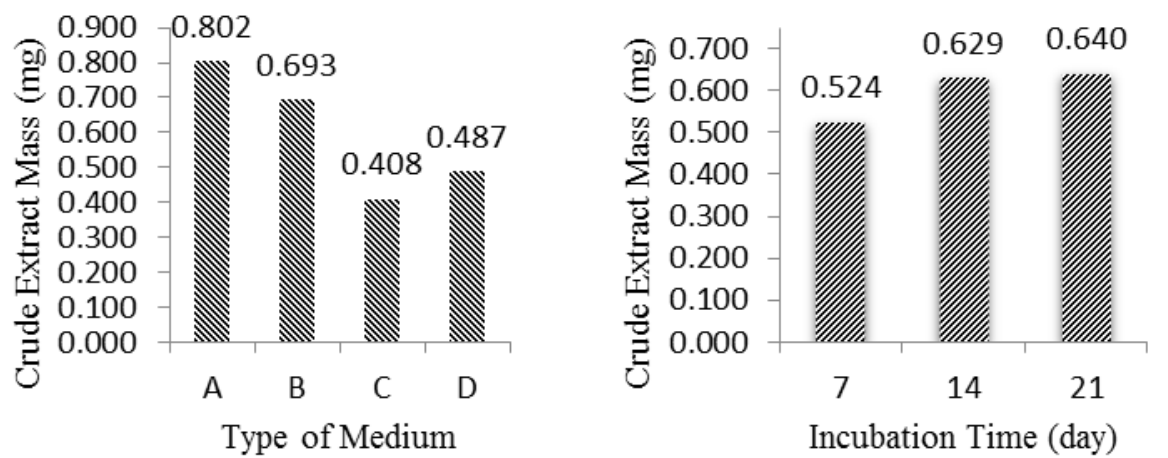

Figure 1. Histogram of crude extract mass (CEM) in different types of medium (left) and incubation times (right). 
Streptomyces sp. SA404 CEM increased in accordance with the increasing MDW (Figure 2).
The highest MDW was found in a medium incubated for 21 days $(448.8 \mathrm{mg})$.

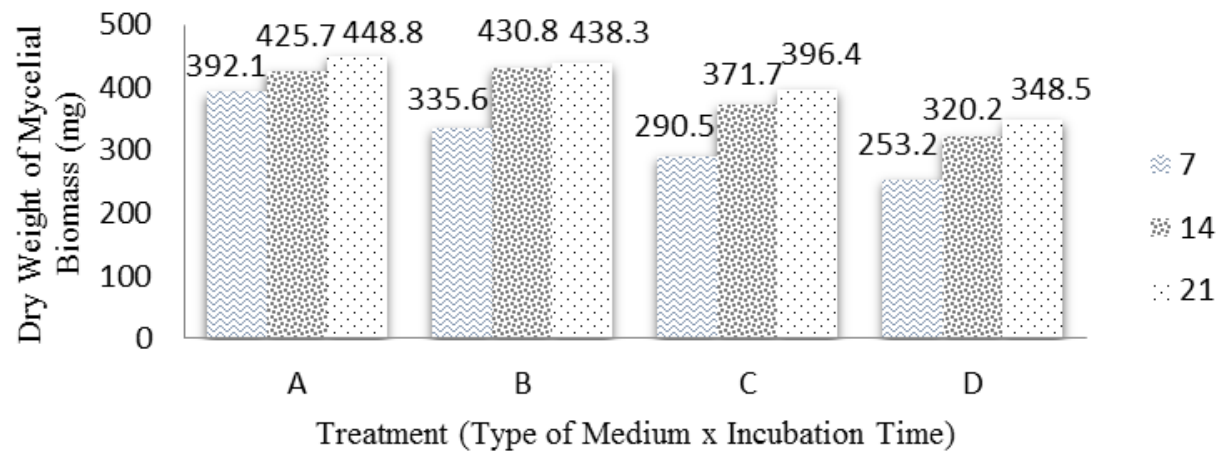

Figure 2. Histogram of mycelial biomass of Streptomyces sp. SA404 on various types of medium and incubation times.

The utilization of sugars (glucose, starch, and oatmeal) as carbon sources by Streptomyces sp. SA404 was indicated by the decreasing sugar concentrations (Figure 3). The decreasing sugar concentrations indicated that the inoculum had consumed sugars as carbon sources. The result also exhibited that the longer the fermentation time, the lower the residual carbon might be resulted. Carbon was used for energy source and mycelium growth. According to the research conducted by [15], the decreasing sugar was also followed by the increasing mycelium biomass.

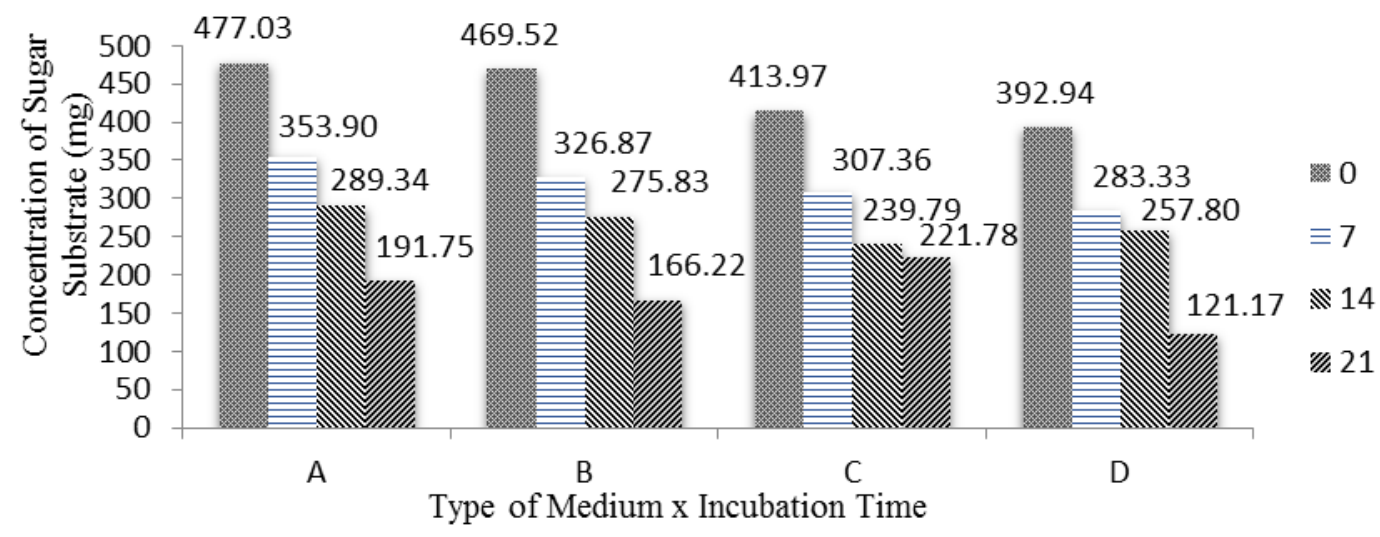

Figure 3. Histogram of sugar reduction concentration

Medium A which was composed of starch and glucose as carbon sources for the Streptomyces sp. SA404 and in accordance with [1] found that the mixture of glucose and starch was the best carbon source for the production of Streptomyces antimicrobial compounds of. [16] reported that the medium composed of starch $(10 \mathrm{~g} / \mathrm{l})$ and glucose $(5 \mathrm{~g} / \mathrm{l})$ produced Streptomyces crude extract $1.22 \mathrm{~g}$ and this was higher when compared to the other media. Carbon source regulation was a factor affecting the microbial metabolism during the fermentation process. Glucose was the most common simple carbohydrate added into the media used as the energy and carbon sources for the bacterial growth. The biochemical compositions of starch contained various soluble sugars to support the initiation of microbial growth and replication. The production of secondary metabolites was often stimulated by the slowly assimilated complex carbon sources like polysaccharides. This phenomenon explained by the fact that glucose caused a catabolic repression, in which enzymes which were responsible for the secondary metabolite biosynthesis were inhibited. 
Medium A was also composed of yeast extract as the nitrogen source. Nutrients were the key nitrogen donors for the biosynthesis of antibacterial compounds. Yeast extract contained high amounts of glutamic and aspartic acids, alanine, lysine, as well as valine and glycine [17].

Streptomyces sp. SA404 incubated during 21 days resulted in the highest crude extract mass. The result was in accordance with the increasing mycelium biomass during the stationary phase. The stationary phase occurred when the microbes had no significant growth, the even stopping altogether and were related to the exhausted nutrients. According to [18], the more the incubation time the more the secondary metabolites were produced and made the microorganisms produced more toxic compounds which potentially inhibited the production of antimicrobial metabolites.

The filtrate of Streptomyces sp. SA404 culture was able to inhibit the growth of Staphylococcus aureus and Escherichia coli (Figure 4). This inhibition activity was due to the presence of antibacterial compounds secreted into the medium. As the highest antibacterial compounds secreted into medium, the inhibition activity of filtrate was higher [9]. Different media and incubation times affected Streptomyces sp. SA404 in inhibiting the growth of E. coli and S. aureus.

According to [19], the level of antibacterial activity could be measured based on the size of the formed inhibitory diameter. The antibacterial agent producing an inhibitory area of $<5 \mathrm{~mm}$ was respectively categorized into weak antibacterial substance; 5-10 $\mathrm{mm}$ was categorized into average antibacterial substance; $10-20 \mathrm{~mm}$ was categorized into strong antibacterial substance; and > $20 \mathrm{~mm}$ was categorized into very strong antibacterial substance.

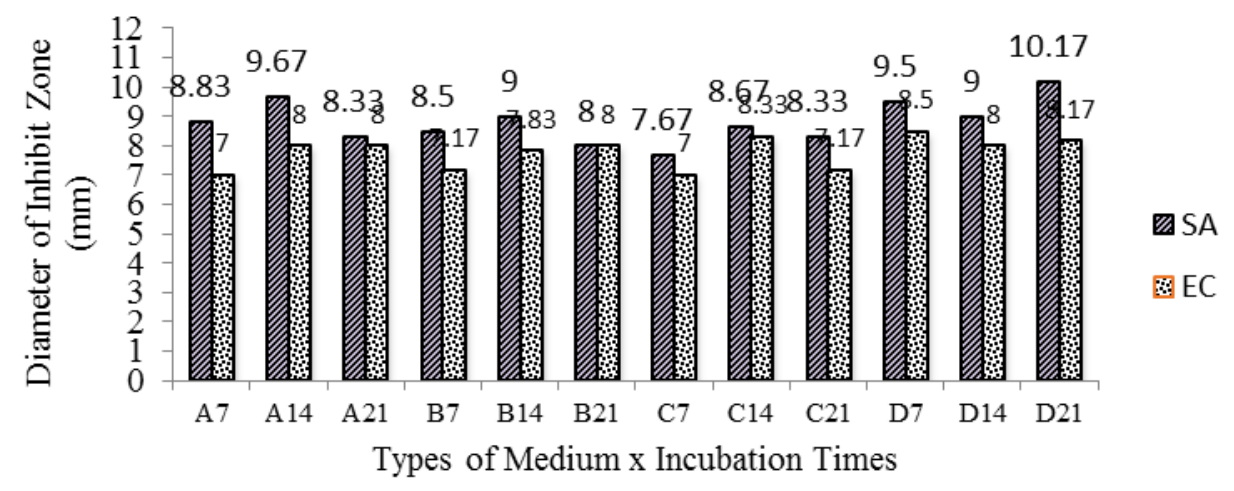

Figure 4. Histogram of inhibition zone diameter of Streptomyces sp. SA404 filtrate against E. coli and $S$. aureus in 8 hours incubation

The crude extract exhibited higher inhibition than that of the filtrate (Figure 5). Crude extract derived from the treatment D14 against S. aureus formed EIZ with the diameter of $29 \mathrm{~mm}$, and was categorized into very strong bacterial substance. Meanwhile, crude extract obtained from B21 against E. coli formed EIZ with the diameter of
$17.5 \mathrm{~mm}$, and was categorized into strong antibacterial substance. Antibacterial activity might be affected by various factors, including carbon and nitrogen sources, oxygen, $\mathrm{pH}$, temperature, ions, some precursors and extraction process, such as the used solvent [20] 


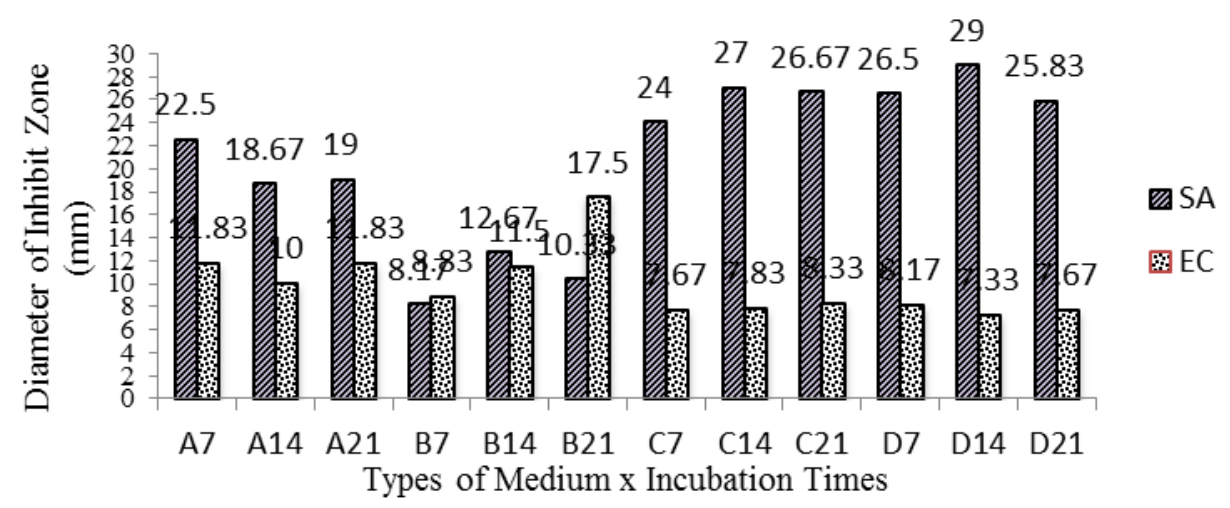

Figure 5. Histogram of inhibition zone diameter of Streptomyces sp. SA404 crude extract against $E$. coli and $S$. aureus in 8 hours incubation

In contrast with medium $\mathrm{A}$, the compositions of medium which produced the extract exhibiting the high inhibitory ability was shown by medium $\mathrm{D}$. Medium A not only presumably produced the antibacterial compounds but also the other metabolites. The filtrate and crude extract of antibacterial substances produced in medium D resulted in the highest inhibition zone against $S$. aureus when compared to those of other media. This indicated that the compositions of oatmeal as a source of carbon and $\mathrm{NaNO}_{3}$ as a source of nitrogen were the best nutrient sources for Streptomyces sp. SA404 to produce the antibacterial compounds.[21] reported that the antibacterial compounds produced by Streptomyces sp. J12 grown in a medium containing starch as a carbon source and $\mathrm{NaNO}_{3}$ as a nitrogen source were capable of inhibiting the growth of Staphylococcus aureus with the inhibition zone diameter of $26 \mathrm{~mm}$. Furthermore, the antibacterial compounds produced by Streptomyces sp. J12 grown in a medium containing oatmeal as a carbon source and $\mathrm{NaNO}_{3}$ as a nitrogen source were capable of inhibiting the growth of Staphylococcus aureus with the inhibition zone diameter of $29 \mathrm{~mm}$.

The highest inhibition formed by Streptomyces sp. SA404 extract against $S$. aureus was in the treatment D14 (EIZ $29 \mathrm{~mm}$ ), while the highest inhibition zone formed by Streptomyces sp. SA404 extract against $E$. coli was in the treatment B21 (EIZ 17,5 mm). Furthermore, the highest crude extract mass was resulted by the Streptomyces sp. SA404 culture in the treatment A21. Thus, the highest or lowest of crude extract mass, did not affect the formed inhibition zone. The more the crude extract mass did not mean the higher the inhibition activity. It was in contrast with the the result of a research conducted by [22] reporting that the high ability of extract inhibition was due to the high of bioactive compound concentration on extract.

\section{CONCLUSION}

Based on the obtained results, it can be concluded that medium types and incubation times significantly affected the growth of Streptomyces sp. SA404 in resulting the crude extract mass. The medium containing glucose and starch as carbon sources and yeast extract as nitrogen source, incubation time 21 days produced the highest crude extract. However, there was no interaction between them in producing crude extract mass. Antibacterial compounds synthesis with 21 days incubation time and the use of inorganic nitrogen further supports the formation of antibacterial compounds.

\section{REFERENCES}

[1] Sathya P and Ushadevi K 2009 Optimization of culturing conditions for improved production of bioactive metabolites by Pseudonocardia sp. VUK-10. Mycobiology 39 pp. 174-81. [3] Ryandini D, Pramono H, Kusharyati D F, Fadlilah F N, Az Zahro F, Muharni R 2018 Antibacterial ability of Streptomyces sp. E404 in different media formula and incubation time and molecular characterization of antibacterial compound encoding gene. The 2nd ICGAB Proceeding, pp 285-95.

[2] Sulistyani N and Akbar A N 2013 Activity of actinomycetes isolate from saweed (Eucheuma cottonii) as antibiotic producer against Staphylococcus aureus and Escherichia coli. JIFI XII 1 pp. 197-200. 
[3] Ryandini D, Pramono H, Kusharyati D F, Fadlilah F N, Az Zahro F, Muharni R 2018 Antibacterial ability of Streptomyces sp. E404 in different media formula and incubation time and molecular characterization of antibacterial compound encoding gene. The 2nd ICGAB Proceeding, pp 285-95.

[4] Basu S, Bose C, Ojha N, Das N, Das J, Pal M and Khurana S 2015 Evolution of bacterial and fungal growth media. Bioinformation XI $4 \mathrm{pp}$. 182-4.

[5] Naikpatil S V and Rathod J L 2011 Selective isolation and antimicrobial activity of rare actinomycetes from mangrove sediment of Karwar. J. Ecobiotechnol. III 10 pp. 26-30.

[6] Brathwaite C W 1981 An introduction to the diagnosis of plant diseases. Costa Rica: IICA.

[7] Kala R R and Chandrika V 1993 Effect of different media for isolation,growth, and maintenance of actinomycetes from mangrove sediments. IJMS XXII 4 pp. 297-9.

[8] El-Naggar M M, El-Assar S A and Shata A M 2017 Production of antitumor agents from novel marine actinomycetes strains isolated from Alexandria, Egypt. J. Antimicrobe III 145 pp. 2472-2512.

[9] Fguira L F, Fotso S, Ameur-Mehdi R B, Mellouli L and Laatsch H 2005. Purification and structure elucidation of antifungal and antibacterial activities of newly isolated Streptomyces sp. strain US80. Res Microbiology XV 3 pp. 341-7.

[10] Srinivasan M C, Laxman R S and Deshpande M V 1991 Physiology and nutritional aspects of actinomycetes: an overview WJMB VII 2 pp. 171-84.

[11] Susilowati D N, Hastuti R D and Yuniarti E 2007 Isolasi dan karakterisasi aktinomisetes penghasil antibakteri enteropatogen Escherichia coli K1.1, Pseudomonas pseudomallei 0205, dan Listeria monocytogenes 5407. J. AgroBiogen III 1 pp. 15-23.

[12] Akbar R A, Ryandini D and Kusharyati D F 2017 Potensi aktinomisetes asal tanah perakaran mangrove segara anakan cilacap sebagai penghasil antifungi terhadap yeast patogen Candida albicans. J. Trop. Biodiv. Biotech, II 2 pp 39-44.

[13]Lee L H, Zainal N, Azman A S, Eng S K, Goh B H, Yin W F, Ab Mutalib N S and Chan K G 2014 Diversity and antimicrobial activities of actinobacteria isolated from tropical mangrove sediments in Malaysia. The Scientific World Journal IV 2 pp. 72-9.
[14] Sudarmadji S, Haryono B dan Suhardi. 1997. Prosedur analisa untuk bahan makanan dan pertanian. Yogyakarta: Liberty Yogyakarta.

[15] Nur $Y$ M, Indrayati $S$, Periadnadi $P$ and Nurmiati N 2018 Pengaruh penggunaan beberapa jenis ekstrak tanaman beralkaloid terhadap produk teh kombucha. J. Bio. UA 16 pp. 6-9.

[16] Kiki M J 2016 A new medium for the isolation and enrichment of actinobacteria. Life Sci $\mathrm{J}$ XIII 1 pp. 1-7.

[17] Mitrovic I Z, Grahovac J A, Dodic J M, Dodic S N, Grahovac M S 2017. Effect of Nitrogen sources on the production of antifungal metabolites by Streptomyces hygroscopicus. J. Nat. Sci. 312 pp.133-9.

[18] Song Q, Huang Y and Yang H 2012 Optimization of fermentation conditions for antibiotic production by actinomycetes yj1 strain against Sclerotinia sclerotiorum. J.Agric.Sci. 47 pp. 95-102.

[19] Davis W W and Stout T R 1971 Disc plate methods of microbiological antibiotic assay Microbiology 522 pp. -65.

[20 Hasani A, Ashraf K and Khosrow I 2013 Streptomycetes: characteristics and their antimicrobial activities. Microbiol Rev 18 pp.63-75.

[21] Al-Zahrani S H 2017 Studies on the antimicrobial activity of Streptomyces sp. isolated from Jazan. JKAU 119 pp.127-38.

[22] Candrasari A, Romas M A and Astuti O R 2011 Uji daya antimikroba ekstrak etanol daun sirih merah (Piper crocatum Ruiz \& Pav.) terhadap pertumbuhan Staphylococcus aureus ATCC 6538, Eschericia coli ATCC 11229 dan Candida albicans ATCC 10231 secara in vitro. Biomedika 14 pp. 25-31. 